\title{
Instantaneous Drill Bit Wear Level Detection in CNC Machine using Wavelet Transform
}

\author{
K Senthil Kumar, L Saravanan, A Balaji
}

\begin{abstract}
The usage of machine tools is widely increased to industrial automation, manufacturing, production technology and etc. The machine tool wear condition monitoring is playing a key role to increase accuracy of the dimension in the final product. By monitoring the wearing level, the life time of the tool is accurately detected and tools can be replaced at the correct time and it can be used to minimize the process time of the task. But it is difficult to monitor and detect the machine tool weariness level from the direct methods. From the indirect methods, the weariness levels of Computer Numerical Control (CNC) machine tool for Acoustic Emission(AE) property is approached in this paper. The AE signals are recorded and preprocessed to extract the features of different wearing conditions using Wavelet Transform(WT). The WT is used to extract the discriminating features that are indirectly reflecting the wearing levels of machine tools. The CNC machines tool weariness at various stage is evaluated from statistical indexes and analyzed based on the relation between the energy distribution of machined surface and wear state of the bit. This approach effectively detects real-time wearing levels of drilling tools by $\mathrm{AE}$ using Wavelet technique.
\end{abstract}

Index Terms: CNC machine; machine tool; acoustic emission; wavelet transform; statistical parameters.

\section{INTRODUCTION}

Drilling is an important tool handling process of design and manufacturing fields with high dimension of accuracy. The choice of a bit depends upon the several factors, first factor is the type of creation to be drilled (Hard, soft, Medium hard or Medium soft), second factor is cost of the tool. Drill weariness checking process is playing an important role to get accurate dimension and automated process [1-2]. Therefore, it is mandatory to develop an accurate, simple and cost effective process with high reliability. One of the most difficulties in wear level monitoring system is to incur the feature information and to correlate the relation between wear condition and $\mathrm{AE}$ signal features during drilling process. The AE sensor has been found to be the effective method for the online drill wear monitoring. Primarily, this paper has been developed for machine tool monitoring under real time condition and to identify the wear with the higher accuracy with the assistance of Wavelet Transform. This transform is an effective tool widely used in all signal processing applications.

Revised Manuscript Received on December 30, 2019.

* Correspondence Author

K Senthil Kumar, Associate Professor, Rajalakshmi Institute of Technology, Department of ECE, Chennai, Tamil Nadu, India (e-mail: senthilkumar.k@ritchennai.edu.in)

L Saravanan, Assistant Professor, Rajalakshmi Institute of Technology, Department of ECE, Chennai, Tamil Nadu, India (e-mail: saravanan.l@ritchennai.edu.in)

A Balaji, Assistant Professor, Rajalakshmi Institute of Technology, Department of ECE, Chennai, Tamil Nadu, India (e-mail: balaji.a@ritchennai.edu.in)

(C) The Authors. Published by Blue Eyes Intelligence Engineering and Sciences Publication (BEIESP). This is an open access article under the CC BY-NC-ND license (http://creativecommons.org/licenses/by-nc-nd/4.0/)

\section{LITERATURE REVIEW}

The applications of automated machine toll process are widely increased in every fields. The AE based process is producing accurate results. The key benefit of using acoustic signal to monitor the tool condition by producing high frequency emission of stored elastic energy as transient elastic stress waves and they are referred as acoustic emission. During cutting process, the transient signals are generated from primary and secondary shear zones. The first shear zone is the dislocation and the second shear zone is the sliding friction and additional shear between the tool flank and the work piece also induces wear in the cutting tool [3]. Power range of $\mathrm{AE}$ signals up to $350 \mathrm{KHZ}$ varies from the tool interface and turn into stable. The total amount of $\mathrm{AE}$ signals is equivalent to drill wear condition, i.e. number of $\mathrm{AE}$ signal occurrences and the number of attempts has been made to track drill weariness [4-6]. The use of AE-based methods of system state monitoring of the turning tool are evaluated with experimented results. AE signals are processed with signal conditioning methods to achieve the most useful signal function.

The spectral analysis of the signal emission was found to be most useful method for drill wear monitoring. Fast Fourier Transform(FFT) analysis is a generally applied technique to wear monitoring the system. The FFT analysis produces good resolution to frequency domain. Therefore, this approach is not suitable for the study of wear tracking. Wavelet transform has good frequency and time domain resolution; it can be synchronized. Wavelet packet transformation has been used to test the drill load control indices for the acoustic emission signal [4].

The experimental result shows that the monitoring system has less sensed ability to the cutting conditions. So that wavelet packet conversion is the most effective way to extract the AE signal function to track device use. The main objective of this work is that to establish an active drill-wear monitoring system based on the conversion of wavelet packets using the $\mathrm{AE}$ signal obtained from the drilling test on a mild steel work piece with high-speed metal drill bits.

\section{DRILLING OBSERVATION}

Due to the difficulties in machine cutting mechanism, several studies made on to measure thrust, torque and power to detect the tool wear faults. It is necessary to develop a reliable tool to monitor the system [5-6].

There are two methods to monitor the weariness conditions: First method is Direct Method using Electrical Resistance, Radioactive, Computer Vision and Optical. The second method is Indirect method using Acoustic Emission, Vibration, Cutting Force and Spindle Motor [3]. 
The Latest trends in the field of tool condition monitoring are the calculation of various system parameters by sensor signals that are indirectly associated with device wear. The indirect form of the product state enables the machine to be tracked remotely and does not disturb the cutting process [3-4]. It is much suitable for the fully automated systems. Recently many attempts were taken to concentrate on the development of this method.

\section{PROPOSED METHOD}

The wavelet packet is derived from a multiresolution sample and wavelet that can be easily done with a time frequency analysis of the signal. Wavelet packet is the positive extension and development of Wavelet Transform which analysis problem of higher frequency but lower distinguish in drill bit wear. Perfect analysis for signal is provided by wavelet packet. Center frequencies that have packet tracking close to or near fault frequency region of interest [7-8]. The control of wavelet transform lies in its frequency resolution with a less number of samples.

A wavelet packet can be defined as a function with multiple integer indices $(\mathrm{J}, \mathrm{K}, \mathrm{N})$

$$
\mathrm{W}_{\mathrm{J}, \mathrm{K}(\mathrm{t})}=2^{\wedge} \mathrm{j} / 2 \mathrm{~W}^{\wedge} \mathrm{n}\left(2^{\wedge} \mathrm{j}(\mathrm{t})-\mathrm{t}\right)
$$

The wavelet packets are used to compute the fast solution for integral equations [7]. The wavelet frequency shift feature is one of the most advanced techniques used for signals in long duration events at low frequencies and short duration events at high frequencies. The octave size of the frequency axis in the conversion to the wavelet may sometimes be seen as a downside of this method. To overcome this, a different method has been introduced based on the principle of wavelet packet transformation. This method produces a linear scale frequency axis at the downside of a lack of excellent time resolution of high frequencies. In wavelet packet analysis, the signals are separated into low and high-frequency elements, which are further defined as approximate and information. Those estimated and detailed sections are then separated from the next stage of estimation and description, and this process is repeated. Wavelet packets are linear wavelet variations. These are the foundations that hold the orthogonality, the smoothness and the locational precisely.

Time dependent signals $f(t)$ : where the WT consists of the computing coefficients of the internal signal components and the wavelet family;

$$
W_{f}(a, b)=J f(t) \Psi^{*}{ }_{a, b}(t) d t
$$

Where

$$
\Psi_{\mathrm{a}, \mathrm{b}}(\mathrm{t})=\frac{1}{\sqrt{|a|}} \Psi\left(\frac{t-b}{a}\right) \mathrm{a}, \mathrm{b} \in \mathrm{R}, \mathrm{a} \neq 0 ; \mathrm{a}
$$

$\mathrm{a}$ and $\mathrm{b}$ are the dilation and translation parameter respectively,

$$
\begin{aligned}
& \mathrm{a}=2^{\mathrm{j}} ; \quad \mathrm{b}=\mathrm{K} 2^{\mathrm{j}}, \mathrm{j}, \mathrm{k} \\
& \Psi_{\mathrm{j}, \mathrm{k}}=2^{-\mathrm{j} / 2} \Psi\left(2^{-\mathrm{j} t}-\mathrm{k}\right)
\end{aligned}
$$

The expression for Discrete Wavelet Transform (DWT), is given by

(4)

$$
\mathrm{C}_{\mathrm{j}, \mathrm{k}}=\mathrm{Jf}(\mathrm{t}) \Psi^{*}{ }_{\mathrm{j}, \mathrm{k}}(\mathrm{t})
$$

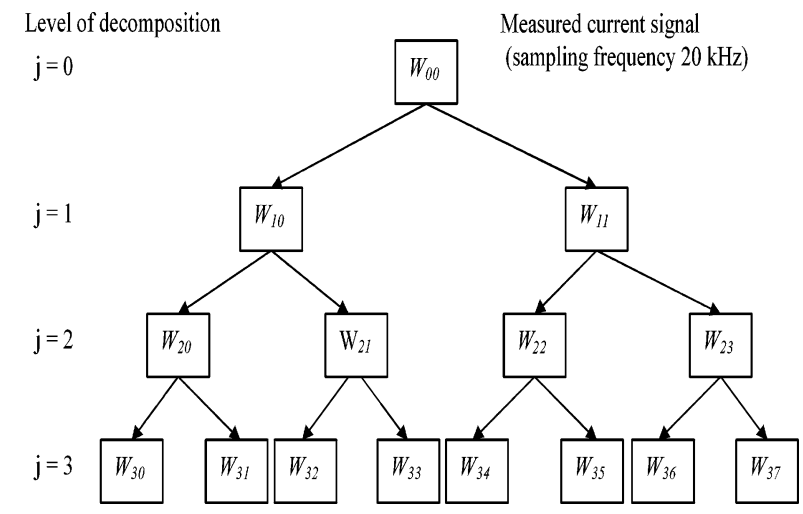

Figure:1. Decomposing of Wavelet.

$$
\begin{aligned}
\phi_{\mathrm{j}, \mathrm{k}} & =2^{-\mathrm{j} / 2} \phi\left(\left(\mathrm{t}-2^{\mathrm{j}} \mathrm{k}\right) / 2^{\mathrm{j}}\right) \\
\mathrm{d}_{\mathrm{j}, \mathrm{k}} & =\int f(t) \phi^{*}{ }_{\mathrm{j}, \mathrm{k}}(\mathrm{t}) \mathrm{dt}
\end{aligned}
$$

where $d_{\mathrm{j}, \mathrm{k}}$ are weightage values for the original sampled signal.

when $\mathrm{j}=0$ : then the sampled signal,

$$
\begin{aligned}
& \mathrm{c}_{\mathrm{j}, \mathrm{k}}=\sum_{\mathrm{n}} \mathrm{X}[\mathrm{n}] \mathrm{h}_{\mathrm{j}}\left[\mathrm{n}-2^{\mathrm{j} k}\right] \\
& \mathrm{d}_{\mathrm{j}, \mathrm{k}}=\sum_{\mathrm{n}} \mathrm{X}[\mathrm{n}] \mathrm{g}_{\mathrm{j}}\left[\mathrm{n}-2^{\mathrm{j}} \mathrm{k}\right]
\end{aligned}
$$

where $\mathrm{x}[\mathrm{n}]$ is discrete -time signal and $h_{j}\left[n-2^{j k}\right]$ is the analysis discrete wavelet, the discrete values $2^{-j / 2}$ and $g_{j}[n-$ $2^{j} k$ ] are weightage factors. At each resolution $j>0$, the scaling coefficients and the wavelet coefficient,

$$
\begin{aligned}
& \mathrm{c}_{\mathrm{j}+1, \mathrm{k}}=\sum_{\mathrm{n}} \mathrm{g}[\mathrm{n}-2 \mathrm{k}] \mathrm{d}_{\mathrm{j}, \mathrm{k}} \\
& \mathrm{d}_{\mathrm{j}+1, \mathrm{k}}=\sum_{\mathrm{n}} \mathrm{h}[\mathrm{n}-2 \mathrm{k}] \mathrm{d}_{\mathrm{j}, \mathrm{k}}
\end{aligned}
$$

An octave-band filter structure is developed for dwt realization and the term $g$ refers high frequency and h refers low frequency filters for the investigation of wavelet and the scaling function.

The DWT can be rewritten as follows

$$
\begin{aligned}
& c_{j}[f(t)]=h(t) * c_{j-1}[f(t)] \\
& d_{j}[f(t)]=g(t) * c_{j-1}[f(t)] \\
& c_{0}[f(t)]=f(t) \\
& H\{\cdot\}=\sum_{k} h(k-2 t) \\
& G\{\cdot\}=\sum_{k} g(k-2 t)
\end{aligned}
$$

then this equation can be written as

$$
\begin{aligned}
& \mathrm{C}_{\mathrm{j}}[\mathrm{f}(\mathrm{t})]=\mathrm{H}\left\{\mathrm{c}_{\mathrm{j}-1}[\mathrm{f}(\mathrm{t})]\right\} \\
& \mathrm{d}_{\mathrm{j}}[\mathrm{f}(\mathrm{t})]=\mathrm{G}\left\{\mathrm{c}_{\mathrm{j}-1}[\mathrm{f}(\mathrm{t})]\right\}
\end{aligned}
$$

DWT is an approximation of $c_{j-1}[f(t)]$ but not the detail 
signal, $\mathrm{dj}_{-1}[\mathrm{f}(\mathrm{t})]$, wavelet Packet transform is

$$
\begin{aligned}
& \mathrm{c}_{\mathrm{j}}[\mathrm{f}(\mathrm{t})]=\mathrm{H}\left\{\mathrm{c}_{\mathrm{j}-1}[\mathrm{f}(\mathrm{t})]\right\}+\mathrm{G}\left\{\mathrm{d}_{\mathrm{j}-1}[\mathrm{f}(\mathrm{t})]\right\} \\
& \mathrm{d}_{\mathrm{j}}[\mathrm{f}(\mathrm{t})]=\mathrm{G}\left\{\mathrm{c}_{\mathrm{j}-1}[\mathrm{f}(\mathrm{t} 0]\}+\mathrm{H}\left\{\mathrm{d}_{\mathrm{j}-1}[\mathrm{f}(\mathrm{t})]\right\}\right.
\end{aligned}
$$

The recursive algorithm applied in the wavelet transform for the $\mathrm{i}^{\text {th }}$ packet on the $\mathrm{jth}$ resolution, $\mathrm{Q}_{\mathrm{j}}^{\mathrm{i}}(\mathrm{t})$ is calculated from

$$
\begin{aligned}
& \mathcal{Q}_{0}{ }^{1}(\mathrm{t})=\mathrm{f}(\mathrm{t}) \\
& \mathrm{Q}_{\mathrm{j}}{ }^{2 \mathrm{i}-1}(\mathrm{t})=\mathrm{HQ}^{\mathrm{i}}{ }_{\mathrm{j}-1}(\mathrm{t}) \\
& \mathrm{Q}^{2 \mathrm{i}}{ }_{\mathrm{j}}(\mathrm{t})=\mathrm{GQ}_{\mathrm{j}-1} \mathrm{i}(\mathrm{t})
\end{aligned}
$$

Where

$$
\begin{aligned}
& t=1,2, \ldots . .2^{j-i,} ; \\
& i=1,2 \ldots ., 2^{j} ; \\
& j=1,2, \ldots . J ; \\
& J=\log _{2} N ; \quad N-\text { Length of the data }
\end{aligned}
$$

In wavelet transform, wavelet packet method is considered as the latest technique for the accurate analyzing of machine tools and fault detection.

\section{FEATURE EXTRACTION}

The output data will be converted into a small set of representation features (also called a vector function) if the input data is too large to be logically equivalent. Standard deviation, which is a wider distance variable is used as a standard range measuring unit. With low standard deviations and for high standard deviations, data points are very similar to the average at various stages over a wide variety of values.

The skewness $\left(\gamma_{1}\right)$ of a random variable $X$ is the third moment and defined as

$$
\begin{aligned}
\gamma 1 & =E\left[\left(\frac{X-\mu}{\sigma}\right)^{3}\right]=\frac{\mu^{3}}{\sigma^{3}} \\
& =\frac{E\left[(X-\mu)^{3}\right]}{\left(E\left[(X-\mu)^{2}\right]^{2} / 3\right)}=\frac{K_{3}}{K_{2} \wedge\left(\frac{3}{2}\right)}
\end{aligned}
$$

Kurtosis is generally derived from the result of fourth cumulate divide by the square of the second cumulate values. This is equal to calculate the ratio of fourth moment around the mean to the square of the variance in the probability distribution and subtract minus 3 .

$$
\gamma 2=\mathrm{k} 4 / \mathrm{k} 22=(\mu 4 / \sigma 4)-3
$$

The standard deviation of a function, $f(x, y)$ can be calculated as

\begin{tabular}{|c|c|c|c|c|}
\hline std dev & variance & skewne & kurtos & 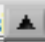 \\
\hline 1.594397 & 2.542103 & 4.68364 & 24.349 & \\
\hline 0.278693 & 0.077670 & 14.3527 & 209.00 & \\
\hline 0.529678 & 0.280559 & $11.986 \mathrm{C}$ & 153.80 & \\
\hline 0.000000 & 0.000000 & $\mathrm{NaN}$ & $\mathrm{NaN}$ & \\
\hline 0.000000 & 0.000000 & $\mathrm{NaN}$ & $\mathrm{NaN}$ & \\
\hline 0.000000 & 0.000000 & $\mathrm{NaN}$ & $\mathrm{NaN}$ & \\
\hline 0.000000 & 0.000000 & $\mathrm{NaN}$ & $\mathrm{NaN}$ & \\
\hline 1.594397 & 2.542103 & 4.68364 & 24.349 & \\
\hline 0.278693 & 0.077670 & 14.3527 & 209.00 & \\
\hline 0.529678 & 0.280559 & $11.986 \mathrm{C}$ & 153.80 & \\
\hline 0.000000 & 0.000000 & $\mathrm{NaN}$ & $\mathrm{NaN}$ & \\
\hline 0.000000 & 0.000000 & $\mathrm{NaN}$ & $\mathrm{NaN}$ & \\
\hline 0.000000 & 0.000000 & $\mathrm{NaN}$ & $\mathrm{NaN}$ & \\
\hline 0.000000 & 0.000000 & $\mathrm{NaN}$ & $\mathrm{NaN}$ & \\
\hline 1.594397 & 2.542103 & 4.68364 & 24.349 & \\
\hline 0.278693 & 0.077670 & 14.3527 & 209.00 & \\
\hline 0.529678 & 0.280559 & $11.986 \mathrm{C}$ & 153.80 & \\
\hline 0.000000 & 0.000000 & $\mathrm{NaN}$ & $\mathrm{NaN}$ & \\
\hline 0.000000 & 0.000000 & $\mathrm{NaN}$ & $\mathrm{NaN}$ & $\mp$ \\
\hline & & & r & \\
\hline
\end{tabular}

$$
\begin{aligned}
& \sigma=\sqrt{ }\left(\left(\sum f(x, y) X D\right) /(\mathrm{MXN})\right) \\
& \mathrm{x}=1,2, \ldots, \mathrm{M} ; \quad \mathrm{y}=1,2, \ldots, \mathrm{N}
\end{aligned}
$$

$\mathrm{x}$ and $\mathrm{y}$ varies. where $\mathrm{D}, \mathrm{M}$ and $\mathrm{N}$ are deviation, the maximum number of elements in row and the maximum number of elements in column respectively. By analyzing total data onto all the holes from the tables (1 to 4 ) and the graph has been plotted using skewness, kurtosis, standard

deviation and variance. At initial stage, the located wear is in the minimum range and increase to time function.

Table:1. Variation of parameter value for $1^{\text {st }}$ hole.

\section{Table}

Table:2. Variation of parameters values for $100^{\text {th }}$ hole. Table

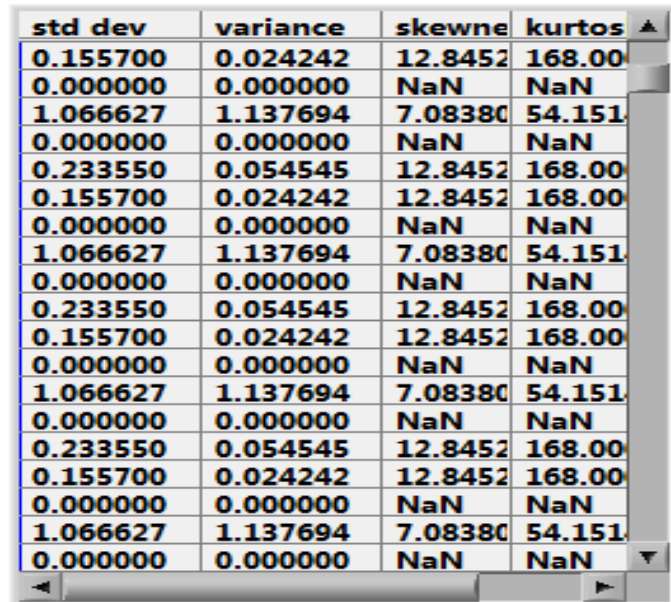

Table:3. Variation of parameter values for $200^{\text {th }}$ hole. Table

\begin{tabular}{|l|l|l|l|}
\hline std dev & variance & skewne & kurtos \\
\hline 3.342038 & 11.169220 & 17.9852 & 349.18 \\
\hline 0.718006 & 0.515533 & 9.30147 & 90.659 \\
\hline 0.331374 & 0.109809 & 16.2477 & 279.63 \\
\hline 0.419056 & 0.175608 & 14.2475 & 204.98 \\
\hline 0.300654 & 0.090393 & 19.4947 & 390.29 \\
\hline 0.197787 & 0.039120 & 20.2237 & 412.00 \\
\hline 3.342038 & 11.169220 & 17.9852 & 349.18 \\
\hline 0.718006 & 0.515533 & 9.30147 & 90.659 \\
\hline 0.331374 & 0.109809 & 16.2477 & 279.63 \\
\hline 0.419056 & 0.175608 & 14.2475 & 204.98 \\
\hline 0.300654 & 0.090393 & 19.4947 & 390.29 \\
\hline 0.197787 & 0.039120 & 20.2237 & 412.00 \\
\hline 3.342038 & 11.169220 & 17.9852 & 349.18 \\
\hline 0.718006 & 0.515533 & 9.30147 & 90.659 \\
\hline 0.331374 & 0.109809 & 16.2477 & 279.63 \\
\hline 0.419056 & 0.175608 & 14.2475 & 204.98 \\
\hline 0.300654 & 0.090393 & 19.4947 & 390.29 \\
\hline 0.197787 & 0.039120 & 20.2237 & 412.00 \\
\hline 3.342038 & 11.169220 & 17.9852 & 349.18 \\
\hline & & & \\
\hline
\end{tabular}


Table:4. Variation of parameter values for $600^{\text {th }}$ hole

\section{Table}

\begin{tabular}{|l|l|l|l|}
\hline std dev & variance & skewne & kurtos \\
\hline 1.658235 & 2.749743 & 19.7248 & 404.58 \\
\hline 0.143182 & 0.020501 & 20.952 & 442.00 \\
\hline 0.429547 & 0.184510 & $20.952 \xi$ & 442.00 \\
\hline 0.000000 & 0.000000 & NaN & NaN \\
\hline 0.000000 & 0.000000 & NaN & NaN \\
\hline 0.000000 & 0.000000 & NaN & NaN \\
\hline 0.000000 & 0.000000 & NaN & NaN \\
\hline 2.610930 & 6.816956 & 9.87527 & 118.00 \\
\hline 1.658235 & 2.749743 & 19.7248 & 404.58 \\
\hline 0.143182 & 0.020501 & 20.9523 & 442.00 \\
\hline 0.429547 & 0.184510 & 20.9523 & 442.00 \\
\hline 0.000000 & 0.000000 & NaN & NaN \\
\hline 0.000000 & 0.000000 & NaN & NaN \\
\hline 0.000000 & 0.000000 & NaN & NaN \\
\hline 0.000000 & 0.000000 & NaN & NaN \\
\hline 2.610930 & 6.816956 & 9.87527 & 118.00 \\
\hline 1.658235 & 2.749743 & 19.7248 & 404.58 \\
\hline 0.143182 & 0.020501 & 20.9523 & 442.00 \\
\hline 0.429547 & 0.184510 & 20.9523 & 442.00 \\
\hline & & & \\
\hline
\end{tabular}

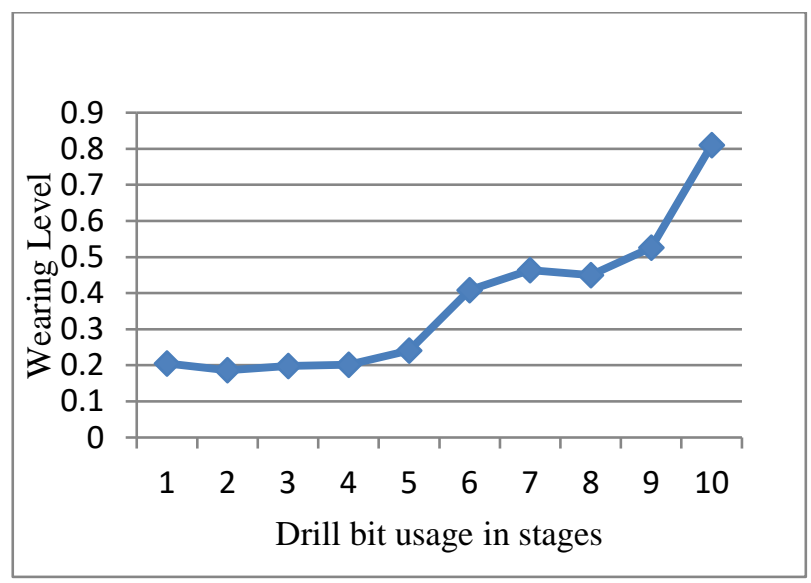

Figure:2. Wearing levels in different stages

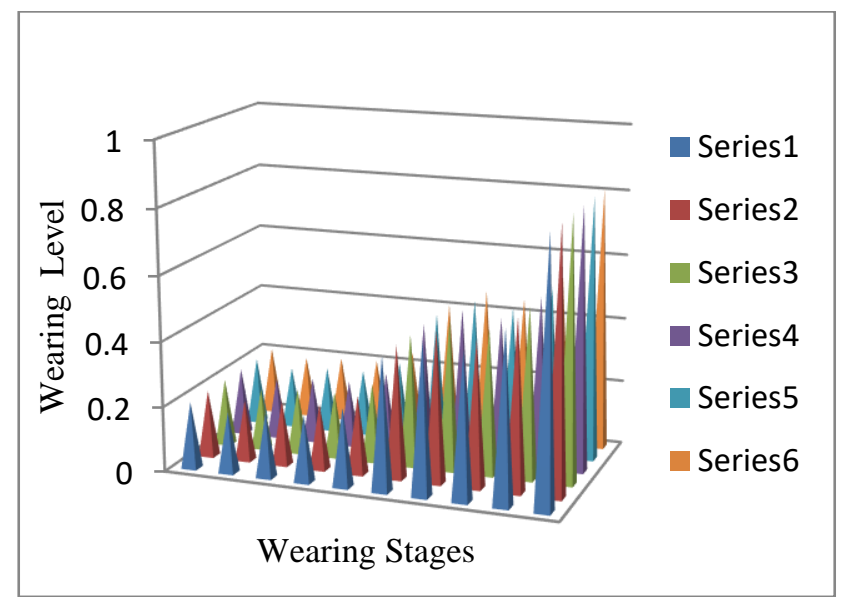

Figure:3. Various levels of wearing stages

The figures (2 and 3) represent weariness of all data clearly. The variation in the above said statistical value of wavelet packet coefficients distinctly shows the wear in real time signals.

\section{RESULT AND DISCUSSION}

The acoustic emission signal from the machine tool is studied generally in the frequency spectrum between $100 \mathrm{KHZ}$ and 1000KHZ. AE detection requires a high sampling rate, distortion, sorting, large data space resource retention and processing speed [4]. While tracking drill wears, the tracked AE signals to provide complicated data onto the real-time cutting process. To ensure the accuracy of the drill-wear tracking and to compare the relationship between the two signal conditions. Wavelet is one of the compact signals for WPT these features are very good for analysis [10]. When the drill is new, the pulse caused by the drill Wear will be lower and the volume of the AE will be low and the cutting mechanism will be constant. As the drill Wear increases, the magnitude also increases. Figure: 4.(a). Analysis of 1st hole using Wavelet. Figure: 4.(b). Analysis of 100th hole using Wavelet Graph: 4.(c). Analysis of 200th hole using Wavelet Graph: 4.(d). Analysis of 600th hole using Wavelet.

These waveforms display the frequency of drill bits to be worn for 1st, 100th, 200th and 600th holes using the transform wavelet box. By comparing the various graphs below (1st, 100th, 200th, 600th hole of the drill bit, the drill bit is worn and lost power in the 600th hole rather than the 1st hole. The value of the wavelet packet coefficients becomes immune to the change in the system level. As the number of holes reduces during the drilling process, the 600th hole is subaltern.

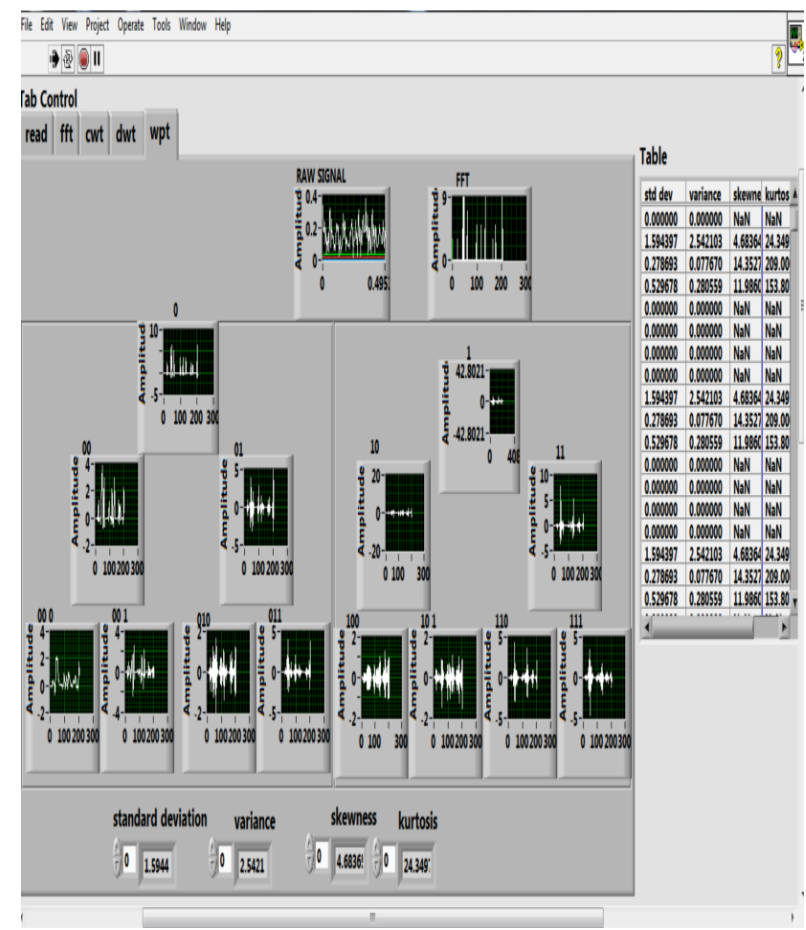

Figure: 4.(a). Analysis of $1^{\text {st }}$ hole using Wavelet.

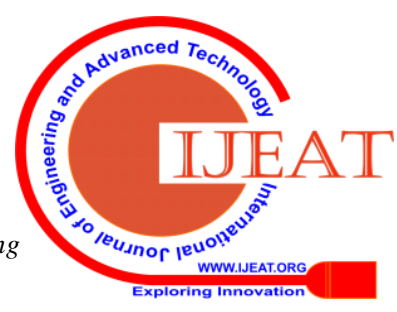




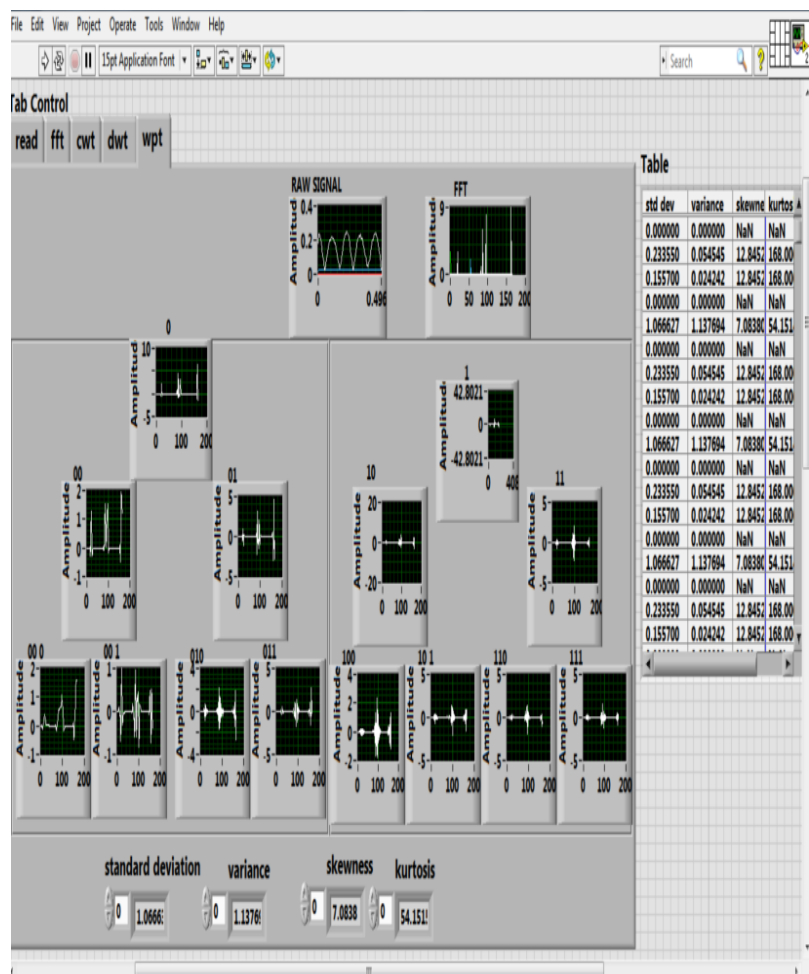

Figure: 4.(b). Analysis of $100^{\text {th }}$ hole using Wavelet

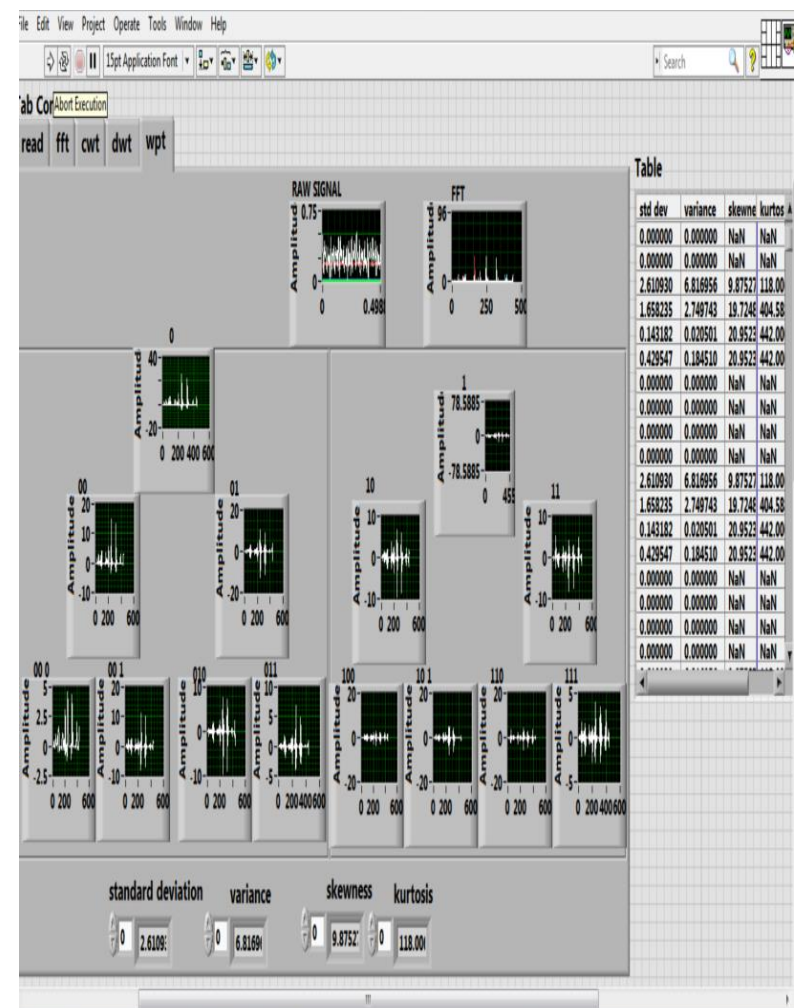

Figure: 4.(c). Analysis of $200^{\text {th }}$ hole using Wavelet

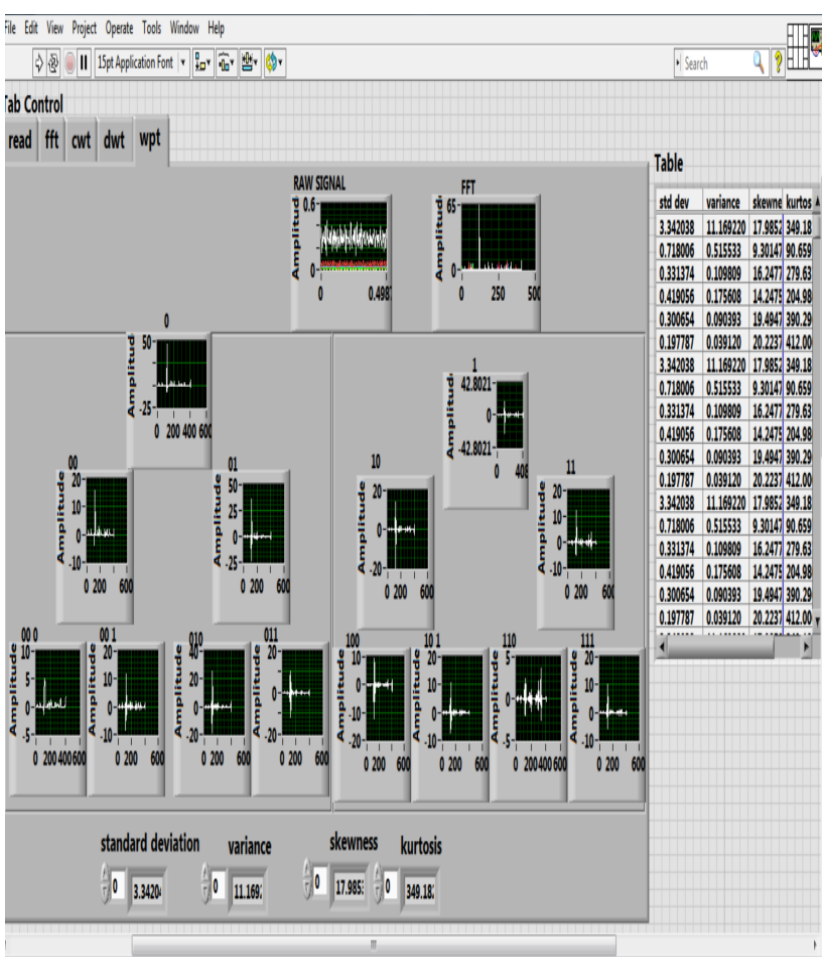

Figure: 4.(d). Analysis of $600^{\text {th }}$ hole using Wavelet.

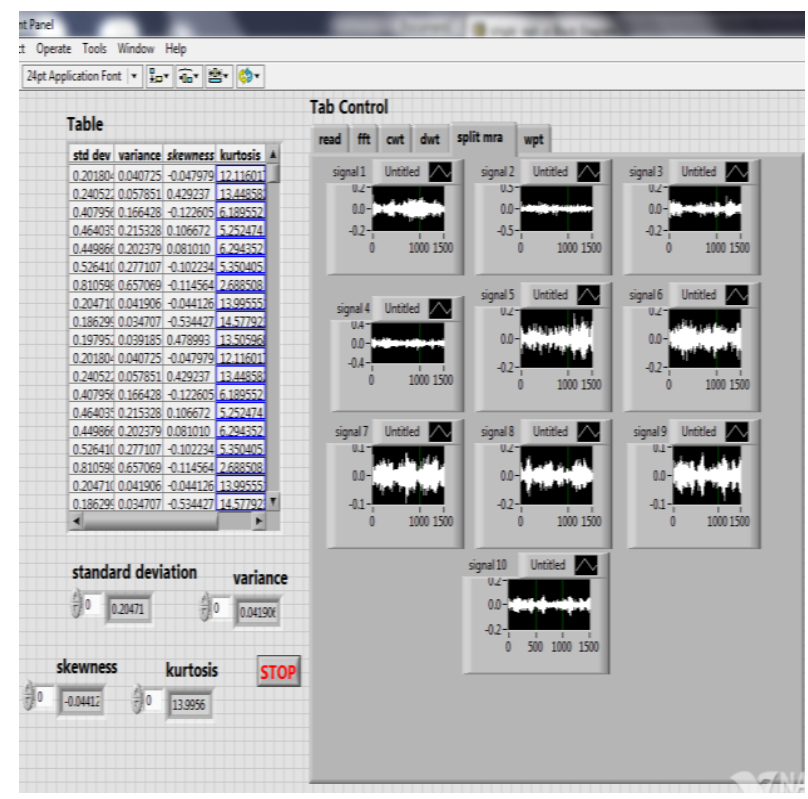

Figure: 4.(e). Drill wear analysis of all data used with Wavelet Transform.

\section{CONCLUSION}

The CNC machines weariness level detection from AE sensor signals using WT is analyzed and found to be an effective real-time machine tool monitoring system. The features derived from Wavelet Transform are used to correlate the state of drill wears and the characteristics of the AE signal to different stages and used to analysis the tool conditions. The obtained result shows that AE sensor based weariness detection using Wavelet Transform can be effectively applied to the real-time machine tool monitoring process.

Published By:

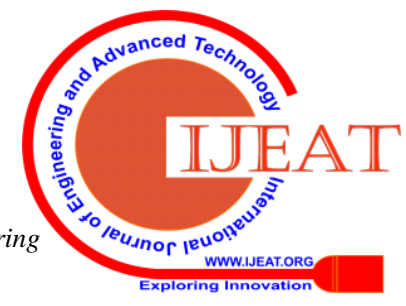




\section{REFERENCES}

1. Karali Patra , Surjya K. Pal \& Kingshook Bhattacharyya, Application of Wavelet Packet Analysis in Drill Wear Monitoring, MCT, An International Journal,vol-11(3), pp:413-432, 2007.

2. Rafezi, Hamed et al., Time Domain and Frequency Spectrum Analysis of Sound Signal for Drill Wear Detection, International Journal of Computer and Electrical Engineering, vol-4(5),pp:722$725,2012$.

3. S.Y.Liang and D.A Dornfield; Tool wear detection using time series analysis of acoustic emission, Transaction of ASME ,vol-111, pp: 195-205,1989.

4. A.Velayudhum,R. Krishnamuruthy and T.Soundarapan -dian, Acoustic emission based drill condition monitoring during drilling of glass /Phenolic Polymeric Composite using wavelet packet transform, International Conference on Recent Advances in Composite Materials ,vol- 412, pp:141-145,2005.

5. G.Byrne,D.Dornfeld,I.Inasaki ,G.Kettler,W.Konig,and R.Teti, Annals of the CIRP,vol-44, pp:541-567, 1995.

6. L.Dan,J.Mathew, Tool Wear and Failure Monitoring techniques for turning : A review ,Int. Journal of machine Tools Manufact,vol30(4) ,pp:579-598, 1990.

7. H. Deng, H. Ling, On a class of predefined wavelet packet bases for efficient representation of electromagnetic integral equations, IEEE Trans. Antennas and Propagation, vol-47(12), pp: 1772-1779,1999.

8. Shihong Wu, Zailin Piao et al. Harmonics Detection in Electric Power Systems Based on Wavelet Packet Transform, International Conference on Intelligent Computation Technology and Automation,pp:425-427, 2010.

9. I.Daubechies, The wavelet transform, time-frequency localization and signal analysis, IEEE trans. on information theory, vol- 36 pp:961-1005,1990.

10. L.Xiaoli, Y.Yingxue, Y.Zhejun, Study on tool condition monitoring using fuzzy neural network, Journal of Harbin Inst.Technol.vol20(4),pp:14-19,1997.

\section{AUTHORS PROFILE}

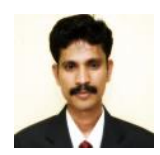

K Senthil Kumar received the Bachelor of Engineering degree in Electronics and Communication engineering from the University of Madras, Tamil Nadu, India, in 2000 and the Master of Engineering degree in Medical Electronics from Anna University, Tamil Nadu, India in 2008. He is currently doing research in time-series analysis of biological signals. His research interests include medical data analysis and IoT in health care applications.

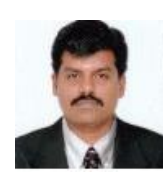

L Saravanan received the B.E. degree in Electronics and Communication Engineering from the University of Madras, Tamilnadu, India, in 2004 and the M.E. degree in Optical Communication from Anna University, Tamilnadu, India in 2008. He is currently working with Automatic Human Brain Tumor Detection in MRI Image. His research interests include medical image processing and IoT in health care applications and energy management systems.

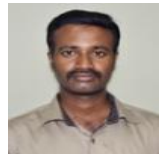

A Balaji received the B.E. degree in Electronics and Communication Engineering from Anna University, Tamilnadu, India, in 2008 and the M.E. degree in Applied Electronics from Anna University, Tamilnadu, India in 2011. He is currently working with Smart Antennas. His research interests include Embedded and IoT applications. 